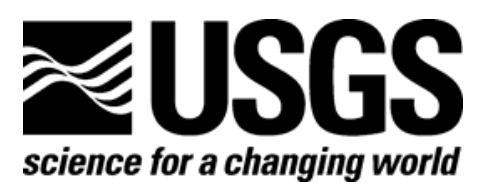

\title{
Pygmy Rabbit Surveys on State Lands in Oregon
}

By Joan Hagar, George Lienkaemper

Open-File Report 2007-1015

U.S. Department of the Interior U.S. Geological Survey 


\section{U.S. Department of the Interior DIRK KEMPTHORNE, Secretary}

\section{U.S. Geological Survey \\ Mark D. Myers, Director}

U.S. Geological Survey, Reston, Virginia 2007

For product and ordering information:

World Wide Web: http://www.usgs.gov/pubprod

Telephone: 1-888-ASK-USGS

For more information on the USGS - the Federal source for science about the Earth, its natural and living resources, natural hazards, and the environment:

World Wide Web: http://www.usgs.gov

Telephone: 1-888-ASK-USGS

Suggested citation:

Hagar, J., Lienkaemper, G. 2007, Pygmy rabbit surveys on state lands in Oregon, U.S. Geological Survey Open-File Report 2007-1015, 23p.

Any use of trade, product, or firm names is for descriptive purposes only and does not imply endorsement by the U.S. Government.

Although this report is in the public domain, permission must be secured from the individual copyright owners to reproduce any copyrighted material contained within this report. 


\section{Contents}

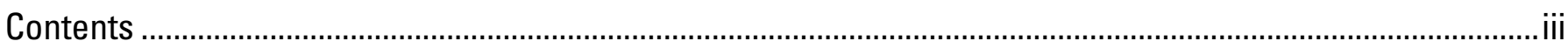

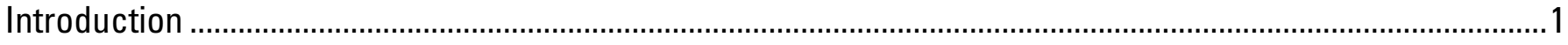

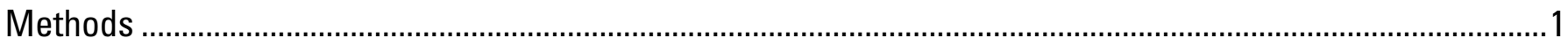

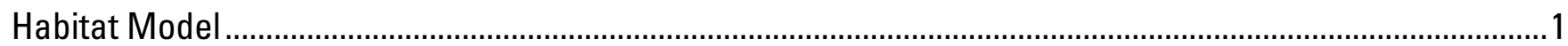

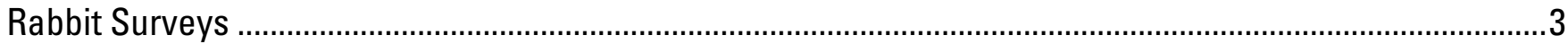

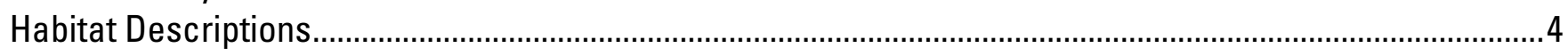

Results

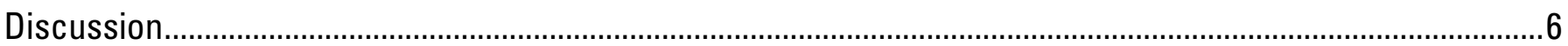

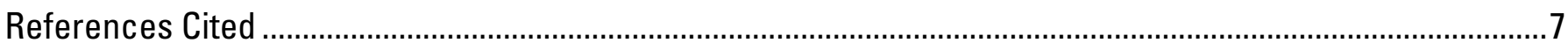

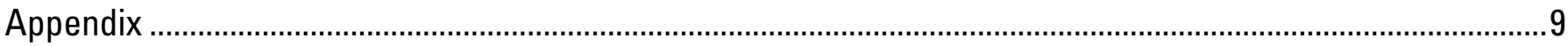

\section{Tables}

1. Summary of results of survey for Pygmy Rabbits in Deschutes, Harney, Lake, and Malheur counties,

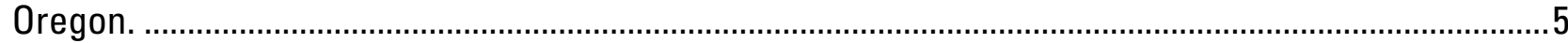

2. Comparison of mean and $95 \%$ confidence intervals for shrub characteristics among active and inactive pygmy rabbit sites, and unoccupied sites.. 5

3. Comparison of average clay and sand content of soil among active and inactive pygmy rabbit sites, and unoccupied sites.

\section{Figures}

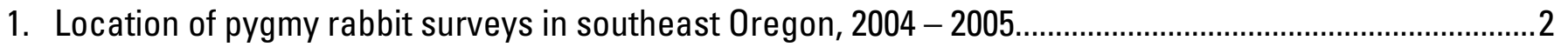




\section{Conversion Factors}

\begin{tabular}{|l|l|l|}
\hline \multicolumn{1}{|c|}{ Multiply } & \multicolumn{1}{c|}{ By } & \multicolumn{1}{c|}{ To obtain } \\
\hline inch (in.) & 2.54 & centimeter $(\mathrm{cm})$ \\
\hline foot (ft) & 0.3048 & meter $(\mathrm{m})$ \\
\hline mile (mi) & 1.609 & kilometer $(\mathrm{km})$ \\
\hline acre & 0.4047 & hectare (ha) \\
\hline
\end{tabular}




\title{
Pygmy Rabbit Surveys on State Lands in Oregon Final Report
}

\author{
By Joan Hagar, George Lienkaemper
}

\section{Introduction}

The pygmy rabbit (Brachylagus idahoensis) is classified by the federal government as a species of concern (i.e., under review by the U.S. Fish and Wildlife Service for consideration as a candidate for listing as threatened or endangered under the Endangered Species Act) because of its specialized habitat requirements and evidence of declining populations. The Oregon Department of Fish and Wildlife (ODFW) lists pygmy rabbits as "sensitive-vulnerable," meaning that protective measures are needed if sustainable populations are to be maintained over time (Oregon Natural Heritage Program, 2001). The Oregon Natural Heritage Program considers this species to be threatened with extirpation from Oregon. Pygmy rabbits also are a species of concern in all the other states where they occur (NatureServe, 2004). The Washington population, known as the Columbia Basin pygmy rabbit, was listed as endangered by the federal government in 2003.

Historically, pygmy rabbits have been collected from Deschutes, Klamath, Crook, Lake, Grant, Harney, Baker, and Malheur Counties in Oregon. However, the geographic range of pygmy rabbit in Oregon may have decreased in historic times (Verts and Carraway, 1998), and boundaries of the current distribution are not known. Not all potentially suitable sites appear to be occupied, and populations are susceptible to rapid declines and local extirpation (Weiss and Verts, 1984). In order to protect and manage remaining populations on State of Oregon lands, Oregon Department of Fish and Wildlife needs to identify areas currently occupied by pygmy rabbits, as well as suitable habitats.

The main objective of this survey was document to presence or absence of pygmy rabbits on state lands in Malheur, Harney, Lake, and Deschutes counties. Knowledge of the location and extent of pygmy rabbit populations can provide a foundation for the conservation and management of this species in Oregon. The pygmy rabbit is just one of a suite of species of concern associated with sagebrush habitats in the Great Basin. Because information on habitat and distribution of many species is scarce, a secondary goal of the rabbit surveys was to list all other vertebrate species encountered on surveyed sites. This information may be useful in directing future studies aimed at specific taxa.

\section{Methods}

\section{Habitat Model}

The priority survey area comprised state lands within the known historic range of suitable habitat for pygmy rabbits, in Malheur, Harney, Lake, and Deschutes Counties (Fig. 1). In order to prioritize areas to survey within the large blocks of state land in this landscape, we developed a 
model to categorize potential habitat suitability for pygmy rabbits according to soil and vegetation characteristics. We also used reconnaissance from the air to identify potential habitat in large state land blocks (see "Rabbit Surveys", next page).

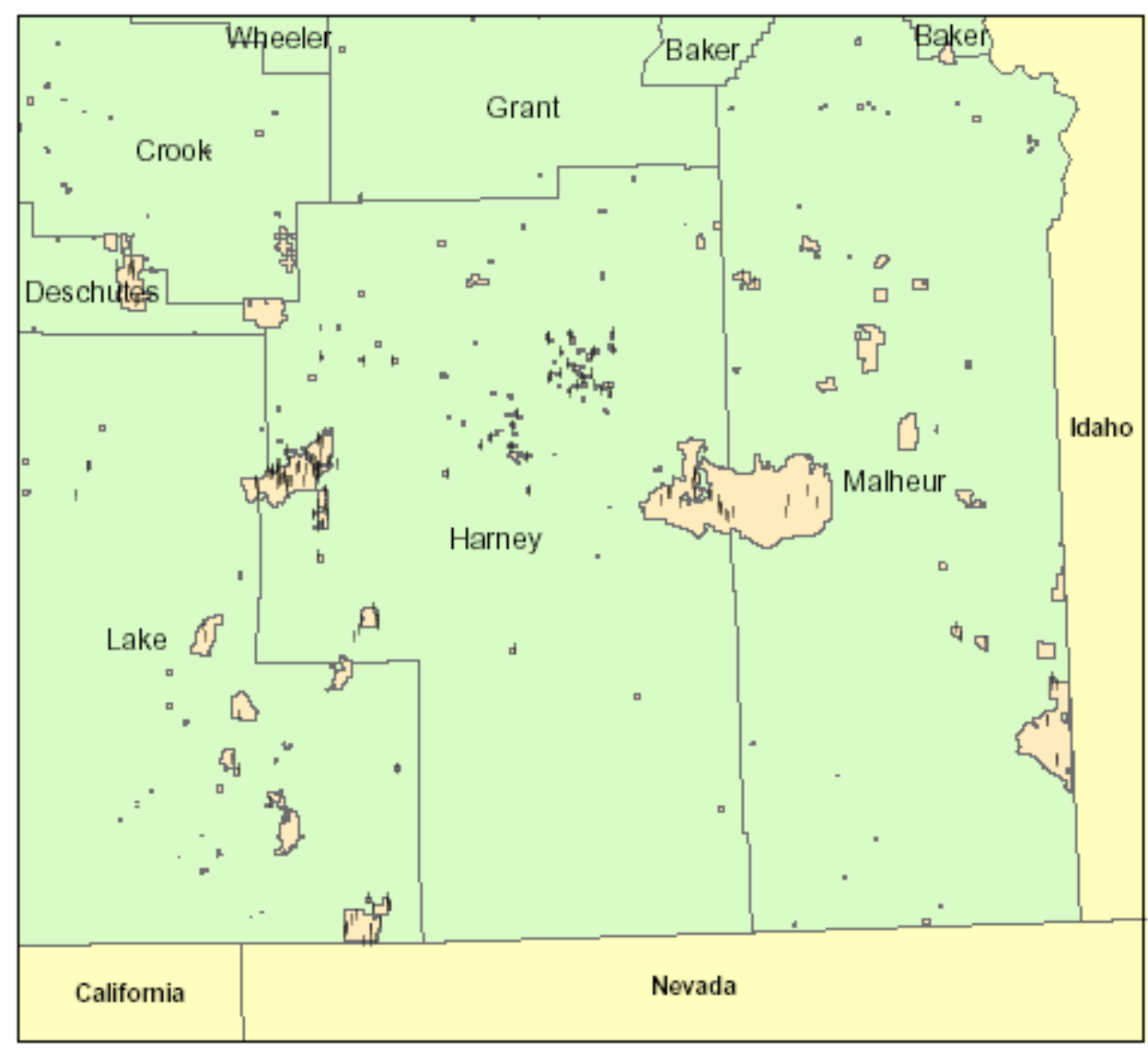

\section{Legend}
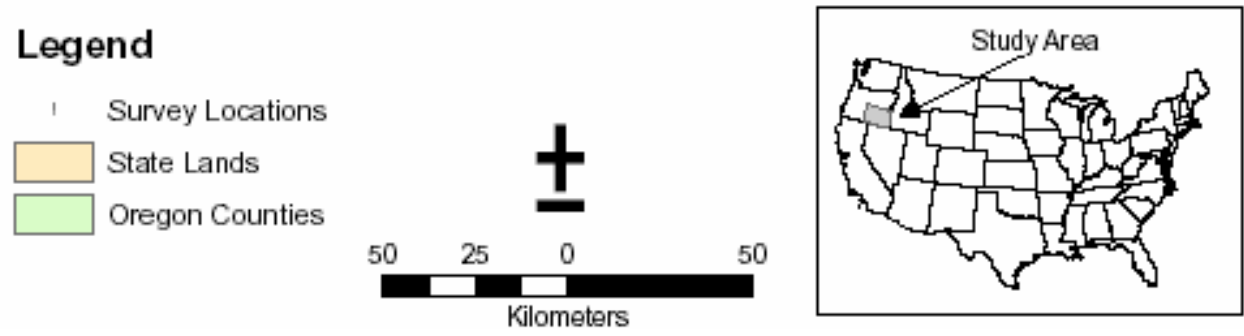

Figure 1. Location of pygmy rabbit surveys in southeast Oregon, $2004-2005$.

Our model was modified from a similar model developed by Rachelow and Svancara (2003). Areas with tree cover, without sage, or with soils less than $61 \mathrm{~cm}$ deep were eliminated from consideration as potential habitat. Because detailed soil data (SSURGO; USDA-NRCS 2005) were not available for the entire study area, we used the statewide (STATSGO; USDA-SCS 1994) soil information in our analysis, recognizing that it is coarser than other detailed soil data. Information about clay content of soils was not available for this data set, so this parameter was not included in the model. In addition, vegetation types were not part of the STATSGO data set, and a sagebrush geographic information system (GIS) layer was used as a surrogate. 
The habitat-potential layer was produced by multiplying scores for each layer in order to clearly differentiate areas of high potential. Based on the primary importance of sagebrush cover to pygmy rabbits, areas with Wyoming big sage were assigned a score of 1 (highest suitability), areas with mountain big sage and mountain low sage were assigned 2, and all other sage types a 3 (lowest suitability). Sage-cover type was determined from the sagebrush layer of "sagestitch" (USGS, 2005). Pygmy rabbits are typically associated with flat topography (Gabler and others, 2000; Rachlow and Svancara, 2003). Therefore, areas with less than $8^{\circ}$ slope were assigned a score of 1 , those with 8 to $20^{\circ}$ slope were assigned a 2 , and steeper areas were assigned a 3 . Slope steepness was determined from SRTM elevation data.

\section{Rabbit Surveys}

We overlaid our model of habitat potential on a map of current (2004) state land ownership boundaries in eastern Oregon, obtained from the Division of State Lands. State land blocks that encompassed areas of at least $1 / 4$ section (32.38 ha) predicted by our model as having very high or high rabbit habitat potential (red and yellow on habitat potential maps) were prioritized for ground surveys. In addition, C. Carey (ODFW Biologist) identified potential habitat from aerial transects flown over large blocks of state land in southeast Lake County, near Wagontire in Harney Coungy, and southeast of New Princeton in Harney and Malheur counties. Universal transverse mercator (UTM) coordinates of suitable patches of tall sage identified from the air as potential habitat were recorded with a global-positioning-system (GPS) unit to facilitate relocation during ground surveys.

Once priority survey sites were identified, we made field visits to all areas predicted as having high or very high rabbit-habitat potential and most areas identified by aerial reconnaissance to determine the presence or absence of rabbits (157 sites ground surveyed). We did not visit approximately 25 of the sites identified from aerial reconnaissance in the large block of state land southeast of New Princeton because our model predicted low habitat potential and the access was very difficult (roadless or required traversing private land). Eleven of the 157 sites were on private land, and were unintentionally surveyed because aerial reconnaissance identified potential habitat adjacent to state lands and boundaries were not clearly marked on the ground.

At each site visited, two observers walked transects spaced no more than $.40 \mathrm{~km}$ apart through at least $75 \%$ of the area of potential habitat, looking for patches that were likely to support centers of pygmy rabbit activity. Because pygmy rabbits and their sign (pellets, burrows) can be detected at any time of day and during any time of year, we did not temporally restrict surveys. Each site was visited one time to determine presence or absence.

We checked patches of tall, dense big sage thoroughly for pygmy rabbits and their burrows, pellets, and tracks. We classified sites according to use status of any burrows that were located (e.g., currently used, apparently unused, or collapsed), and presence and age of pellets. Presence of fresh pellets, open burrows, or sighting of pygmy rabbits provided evidence for classifying a site as "active" (occupied by pygmy rabbits at the time of the survey). We classified sites as inactive if old pellets or collapsed burrows were found in suitable habitat. An inactive classification indicated that pygmy rabbits had used the site but were no longer present. Sites without evidence of occupancy by pygmy rabbits (no pellets, no burrows) were classified as "no rabbits."

The legal and UTM coordinates of all survey routes and burrows were recorded using a GPS unit. Areas that were surveyed but did not have sign of pygmy rabbits also were described along with location data. Surveys were conducted from September 2004 to November 2005. 


\section{Habitat Descriptions}

We used a line-point intercept method (Elzinga and others 2001) to describe shrub cover in $10 \times 10-m$ plots centered on burrows at nine sites occupied by pygmy rabbits and three inactive sites. We did not collect habitat data at active rabbit sites on private land. We sampled vegetation on five parallel $10-\mathrm{m}$ long transects spaced at $2.5 \mathrm{~m}$ intervals. We dropped a pin flag every $50 \mathrm{~cm}$ along each transect and recorded the species of shrub intercepted in the canopy, and whether grass, forbs, or litter were intercepted below the shrub canopy. At three sites where no rabbit sign was detected, we randomly centered vegetation-sampling plots. Average shrub cover and height was compared among the three categories of burrow status using ANOVA with a least square means multiple comparison procedure.

We collected soil samples from burrows at 10 occupied sites, 3 inactive sites, and 5 unoccupied sites. Soil samples were classified by texture (USDAA textural class) and analyzed for sand and clay content at the Soil Physical Characterization Lab at Oregon State University.

\section{Results}

Of the 262,725 ha of state lands in eastern Oregon (Fig. 1), 181,438 ha were unsuitable as pygmy rabbit habitat based on vegetation type (i.e., not sage). Of the remaining area, 76,890 ha ( $29 \%$ of total state land area) were classified as high-to-medium habitat potential by our model, and 4,397 ha $(2 \%)$ were classified as low potential.

Only $11 \%$ of the 157 sites surveyed had evidence of occupancy by pygmy rabbits at the time of the survey, and an additional $9 \%$ had evidence that pygmy rabbits had used the site previously but were no longer present (Table 1). All active sites and most inactive sites were located in Harney and Lake counties; only one inactive site was in Malheur County. Maps of sites surveyed overlain on habitat potential as predicted by our model are in Appendix A.

Rabbit-occupancy status was correlated with variation in shrub cover and height. Active sites had greater average shrub cover than inactive or unoccupied sites (Table 2). Furthermore, the maximum cover at inactive sites barely overlapped the minimum at active sites. Unoccupied sites had notably low cover of shrubs. Shrub cover of $20-40 \%$ is considered marginal habitat for pygmy rabbits (Green and Flinders 1980, Katzner and Parker 1997). More than 40\% cover provides suitable habitat. We sampled vegetation at very few unoccupied sites because it was obvious that shrub cover was well below that required to be suitable habitat for pygmy rabbits (i.e., less than $20 \%$ ) at the vast majority of sites. A coarser method of describing vegetation, such as characterizing cover classes from remote sensing data, would be a more efficient and cost effective means than line-point intercepts for characterizing differences in cover between occupied and unoccupied sites.

Shrub height also is an important habitat feature for pygmy rabbits, and is positively associated with habitat suitability. Average shrub heights reported for occupied sites and burrow locations are typically greater than $65 \mathrm{~cm}$ (Green and Flinders, 1980; Weiss and Verts, 1984). The shrub heights we observed for both active and inactive sites were therefore consistent with suitable habitat reported from other studies (Table 2).

Because pygmy rabbits dig their own burrows, soil texture and content is very important. Suitable soils have greater sand and less clay (usually less than 18\%; Gabler, 1997; Rachlow and Svancara, 2003). These proportions of sand and clay seem to provide the optimum balance between ease of burrow excavation and resistance to collapse. The soil composition we observed at active and previously occupied sites was close to what would be expected for suitable habitat. Soil composition was similar across all sites (Table 3). Similarly, we found no obvious difference in soil textural classification among sites of different occupancy status. Soils at active rabbit sites 
fell into four textural classes: sandy loam (six sites), silt loam (two sites), loam (one site), and loamy sand (one site). Inactive sites were classified as sandy loam (one site) and loam (two sites). Unoccupied sites were classified as sandy loam (three sites), silt loam (one site), and loam (one site).

Table 1. Summary of results of survey for Pygmy Rabbits in Deschutes, Harney, Lake, and Malheur counties, Oregon. Active rabbit sites had evidence of occupancy by pygmy rabbits at the time of the survey; Inactive sites had evidence that pygmy rabbits had used the site but were no longer present; No rabbit sites had no evidence of occupancy by pygmy rabbits.

\begin{tabular}{lllll}
\hline Ownership & \# Sites Surveyed & Active Rabbits & Inactive & No Rabbits \\
\hline State & 143 & 9 & 13 & 121 \\
BLM & 3 & 1 & 0 & 2 \\
Private & 11 & 8 & 1 & 2 \\
$\quad$ Totals & 157 & 18 & 14 & 125 \\
\hline
\end{tabular}

Table 2. Comparison of mean and $95 \%$ confidence intervals for shrub characteristics among active and inactive pygmy rabbit sites, and unoccupied sites. Means with different letters are significantly different $(P<0.10$, ANOVA).

\begin{tabular}{lllllllll}
\hline & \multicolumn{3}{l}{ Shrub Cover (\%) } & \multicolumn{5}{c}{ Shrub Height (cm) } \\
\hline Status & $\mathrm{N}$ & Mean & $95 \% \mathrm{Cl}$ & & $\mathrm{N}$ & Mean & $95 \% \mathrm{Cl}$ \\
Active & 9 & $57 \mathrm{~A}$ & 50.6 & 62.8 & 8 & $86 \mathrm{~A}$ & 69.8 & 103.0 \\
Inactive & 3 & $40 \mathrm{~B}$ & 29.8 & 50.8 & 3 & $76 \mathrm{AB}$ & 49.1 & 103.3 \\
No rabbits & 3 & $34 \mathrm{~B}$ & 23.5 & 44.5 & 3 & $58 \mathrm{~B}$ & 30.5 & 84.7 \\
\hline
\end{tabular}


Table 3. Comparison of average clay and sand content of soil among active and inactive pygmy rabbit sites, and unoccupied sites.

\begin{tabular}{llll}
\hline Status & $\mathbf{N}$ & Clay (\%) & Sand (\%) \\
\hline Active & 10 & 12 & 58 \\
Inactive & 3 & 12 & 52 \\
No rabbits & 5 & 9 & 53 \\
\hline
\end{tabular}

\section{Discussion}

The most important factors influencing habitat suitability for pygmy rabbits include vegetation composition (i.e., sage), shrub cover, shrub height, and soil characteristics. The status of pygmy rabbit occupancy on the sites we surveyed did not vary with vegetation composition or soil characteristics because all sites surveyed were dominated by big sage, and soil characteristics were similar across sites. The variables that seemed to best account for differences in occupancy status among sites were shrub cover and height. All of the sites we surveyed had evidence of cattle grazing, and in many areas it was evident that heavy use by cattle had resulted in a decrease of shrub cover. In addition to reducing shrub cover through trampling, grazing by cattle also has been reported to reduce the nutritional quality of forage for pygmy rabbits (Thines and others, 2004). Thus, many of the sites where we found no evidence of pygmy rabbit occupancy may have had the potential to support pygmy rabbits, as predicted by our model, but habitat may have been rendered unsuitable due to insufficient shrub cover as a result of heavy grazing.

In addition to the patch-level habitat characteristics investigated in this survey, factors operating at larger spatial scales also likely have an important influence on site occupancy by pygmy rabbits. Although pygmy rabbits are apparently capable of dispersing among patches of appropriate habitat in landscapes patterned by natural processes (Katzner and Parker, 1998), increasing fragmentation of sagebrush cover from anthropogenic sources may limit successful dispersal (Weiss and Verts, 1984). Thus, localized populations of pygmy rabbits that become isolated by habitat fragmentation may become extinct, and potentially suitable habitat patches may remain unoccupied if they are too small or too distant from source habitats. Little information is currently available to assess effects of fragmentation on pygmy rabbit habitat use and population dynamics. Future research to investigate the influence of landscape level habitat patterns on patch occupancy by pygmy rabbits would help fill this information void. Using location data from this and other surveys, GIS models could identify thresholds of minimum patch size that currently support pygmy rabbit populations. Combining this approach with information from current investigations of dispersal distances (e.g., T. Forbes' work), maximum inter-patch distances also could be estimated. In addition, genetic analysis could be used to evaluate effects of fragmentation on diversity and variation of genetic material among metapopulations. 


\section{References Cited}

Buol, S.W., Southard, R.J., Graham, R.C., and McDaniel, P.A., 2003, Soil genesis and classification, Fifth edition, Iowa State Press, Ames, USA.

Comer, P., Kagan, J., Heiner, M., and Tobalske, C., 2002, Current distribution of sagebrush and associated vegetation in the western United States (excluding New Mexico and Arizona), Interagency Sagebrush Working Group.

Elzinga, C.L., Salzer, D.W., Willoughby, J.W., and Gibbs, J.P., 2001, Monitoring plant and animal populations, Blackwell Publishing, Malden, Mass.

Gabler, K.I., 1997, Distribution and habitat requirements of the pygmy rabbit (Brachylagus idahoensis) on the Idaho National Engineering and Environmental Laboratory, M.S. thesis, Idaho State University, Boise, Idaho.

Gabler, K.I., Laundre, J.W., and Heady L.T., 2000, Predicting the suitability of habitat in southeast Idaho for pygmy rabbits, J. Wildl. Manage., v. 64(3), p. 759-764.

Green, J.S., and Flinders, J.T., 1980, Habitat and dietary relationships of the pygmy rabbit, J. Range Manage., v. 33, p. 136-142.

Katzner, T.E., and Parker, K.L., 1997, Vegetative characteristics and size of home ranges used by pygmy rabbits (Brachylagus idahoensis) during winter, J. Mammal., v 78 p. 1063-1072.

Katzner, T.E., and Parker, K.L., 1998. Long-distance movements from established burrow sites by pygmy rabbits (Brachylagus idahoensis) in southwestern Wyoming, Northwestern Naturalist v. 7, p. 72-74.

NatureServe, 2004, NatureServe Explorer: An online encyclopedia of life [web application], Version 3.1, NatureServe, Arlington, Virg., Available http://www.natureserve.org/explorer, Accessed May 18, 2004.

Oregon Natural Heritage Program, 2001, Rare, Threatened and Endangered Species of Oregon, Oregon Natural Heritage Program, Portland, Oreg.

Rachlow, J., and Svancara, L., 2003, Pygmy rabbit habitat in Idaho, University of Idaho, Moscow, Idaho, Unpublished report.

Thines, N.J.S., Shipley, L.A., and Sayler, R.D., 2004, Effects of cattle grazing on ecology and habitat of Columbia Basin pygmy rabbits (Brachylagus idahoensi, Biological Conservation, v. 119 , p. 525-534.

Ulmschneider, H., Hays, D., Roberts, H., Rachlow, J., Forbes, T., Himes, J., Sequin, E., Haworth, M., Katzner, T., Kozlowski, A., Rauscher, R., Lauridson, P., 2004, Surveying for pygmy rabbits (fourth draft), U.S. Department of the Interior, Bureau of Land Management, Owyhee Field Office, Boise, Idaho. 
USDA-SCS (U.S. Department of Agriculture, Soil Conservation Service), 1994, State Soil Geographic (STATSGO) data base for Oregon, U.S. Department of Agriculture, Soil Conservation Service, Fort Worth, Texas.

USGS, Forest and Rangeland Ecosystem Science Center, Snake River Field Station, 2005, Current distribution of sagebrush and associated vegetation in the Columbia Basin and Southwestern Regions, U.S. Geological Survey, Corvallis, Oreg.

Verts, B.J., and Carraway, L.N., 1998, Land mammals of Oregon, University of California Press, Berkeley, p. 128-131.

Weiss, N.T., and Verts, B.J., 1984, Habitat and distribution of pygmy rabbits (Sylvilagus idahoensis) in Oregon, Great Basin Naturalist v. 44, p. 563-571.

Welch, B.L., 2005, Big sagebrush: A sea fragmented into lakes, ponds, and puddles, U.S. Department of Agriculture, Forest Service, Rocky Mountain Research Station, General Technical Report RMRS-GTR-144, Fort Collins, Colo. 


\section{Appendix}

Pygmy Rabbit habitat potential and locations of rabbit surveys in Deschutes, Harney, Lake, and Malheur Counties, Oregon 2004 - 2005. Master figure below indicates the page number in Appendix A where each map is displayed. The numbers shown on the figure below correspond with page numbers as follows:

₹USGS

Pygmy Rabbit Survey Areas in SE Oregon

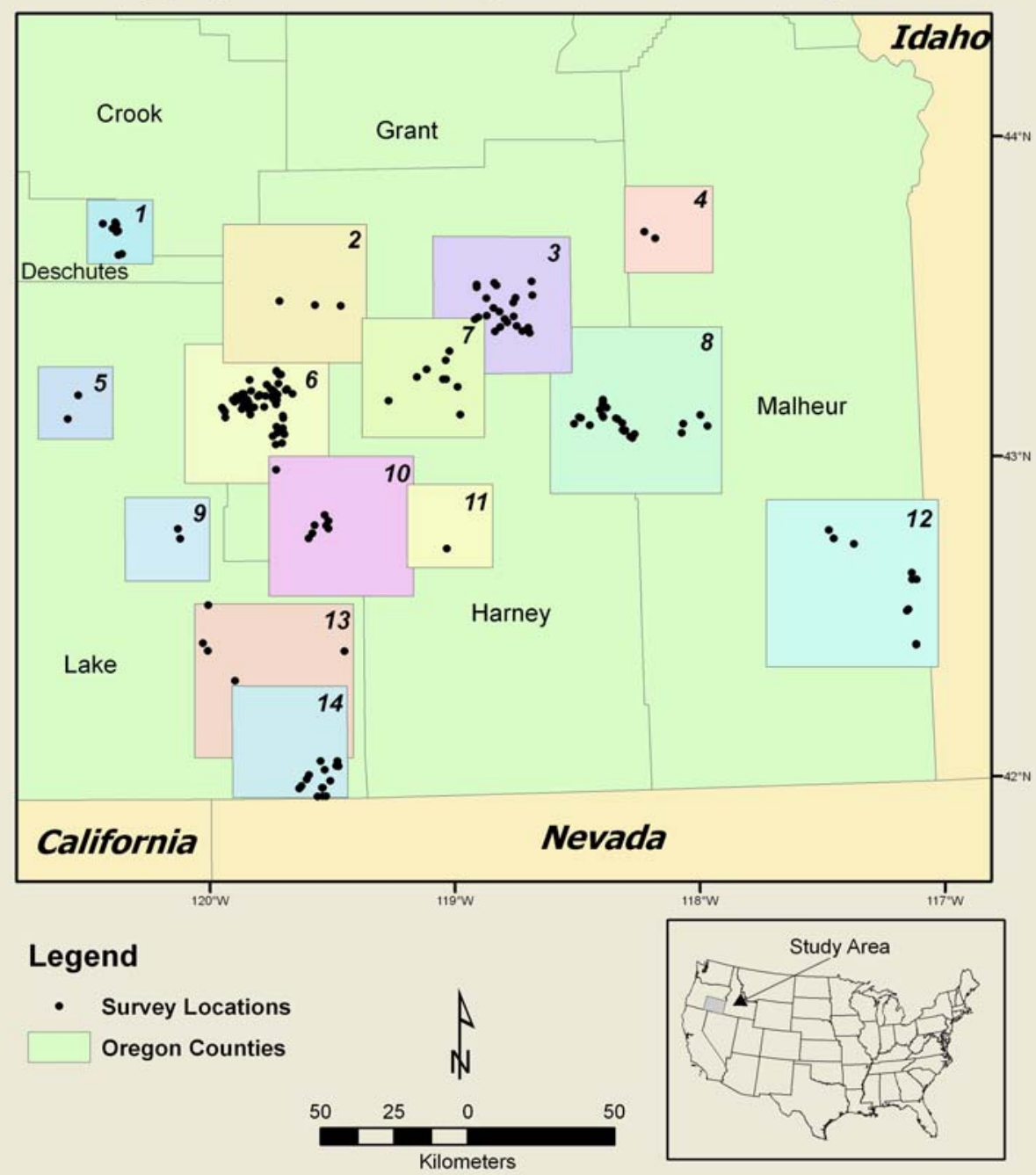




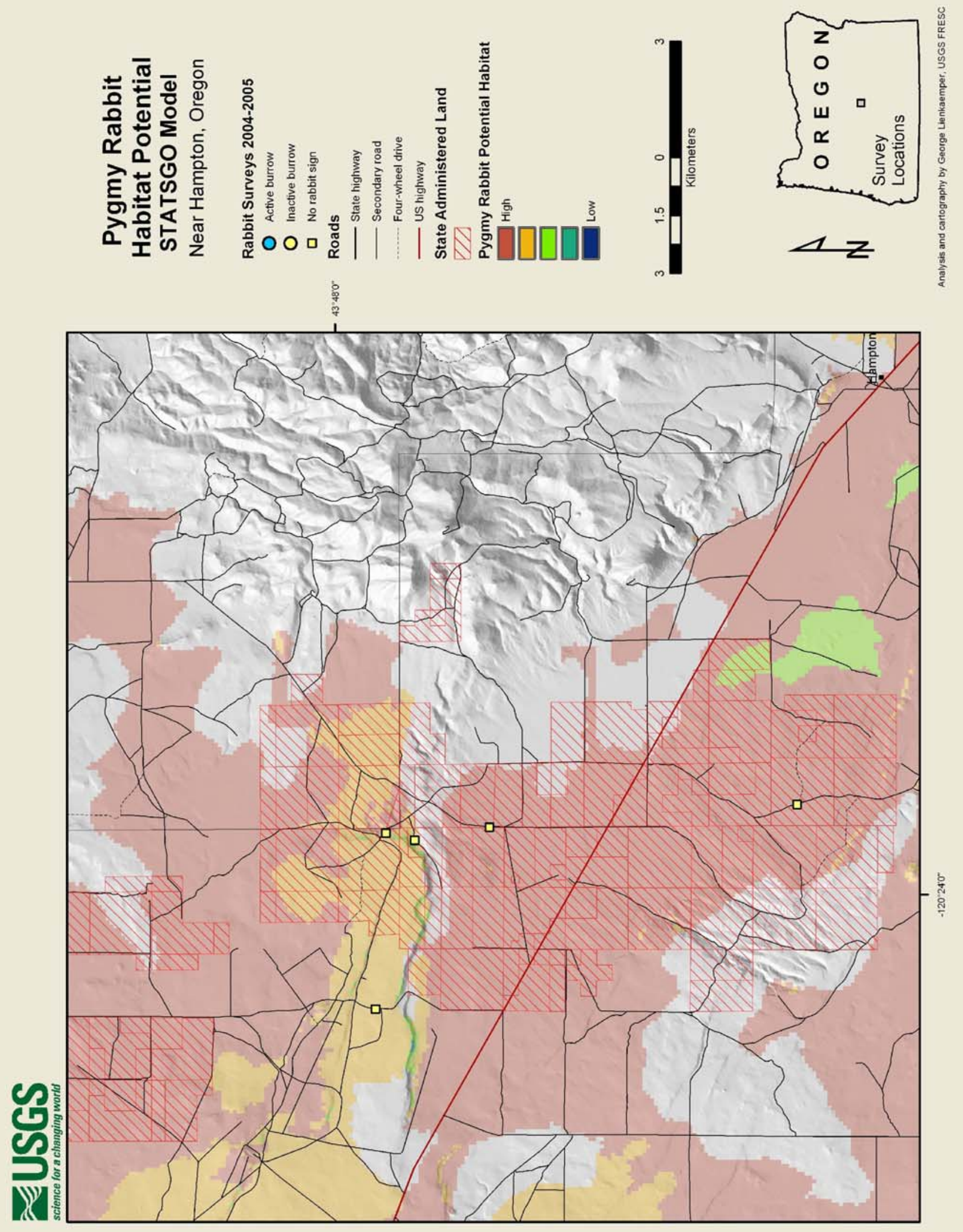




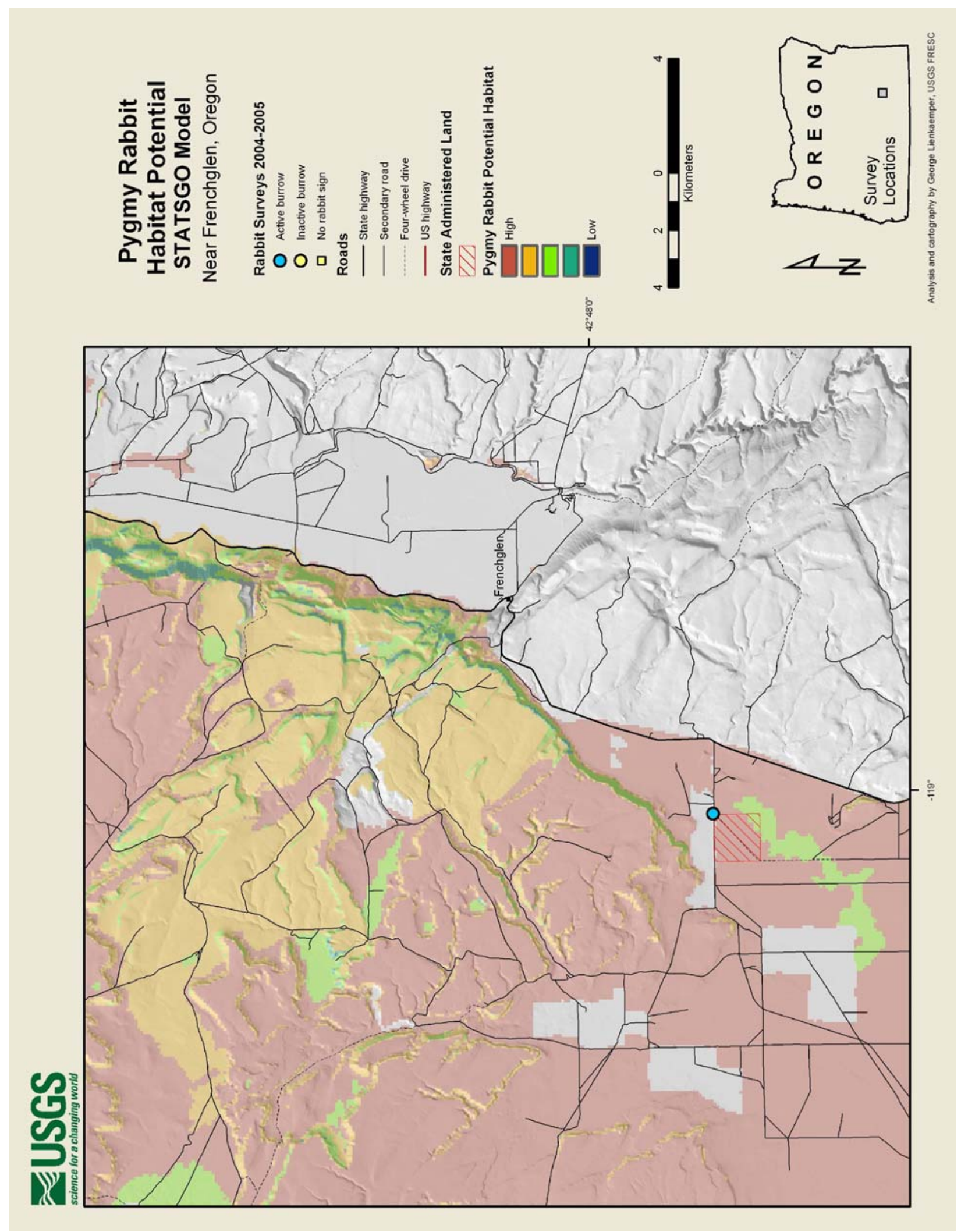




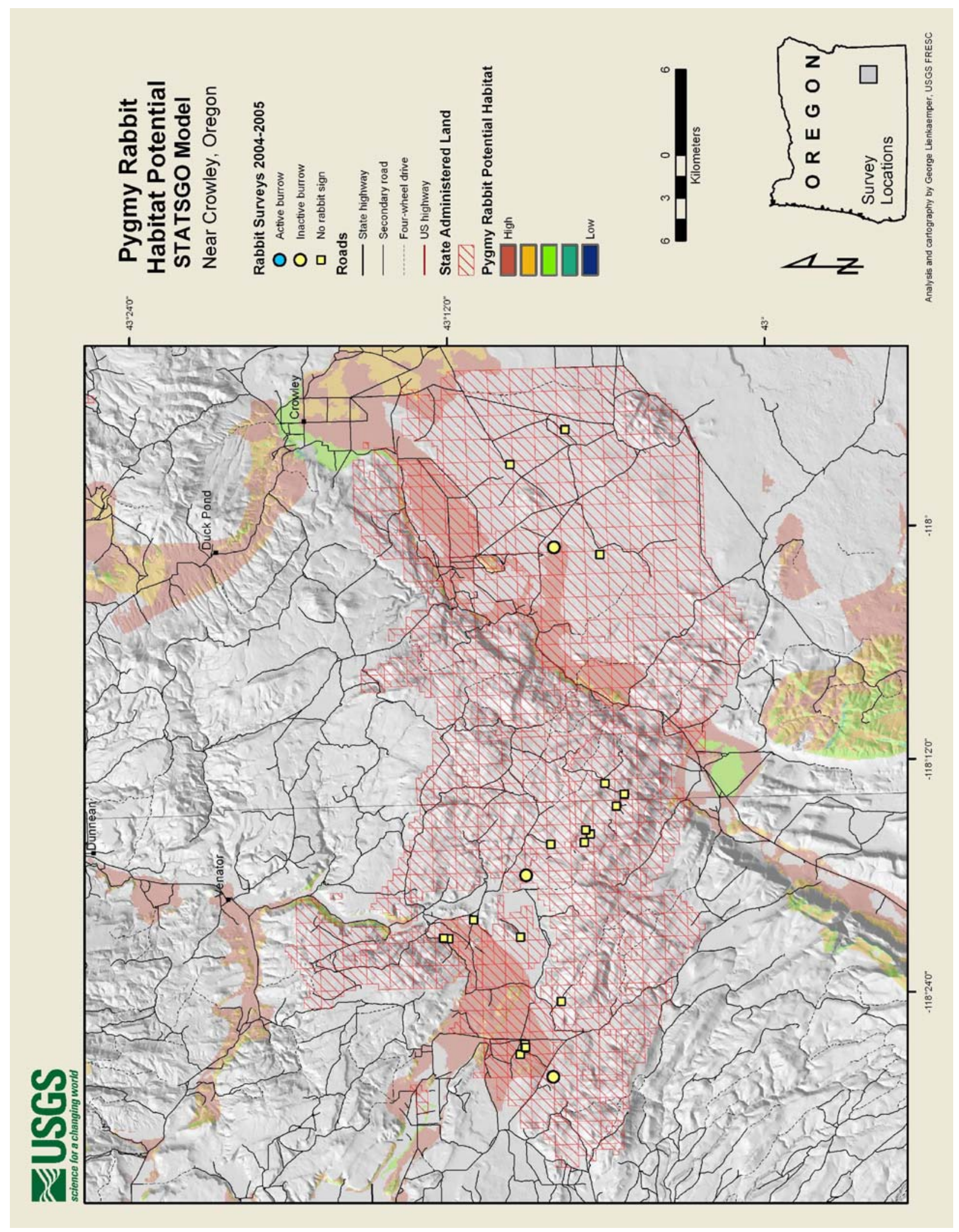




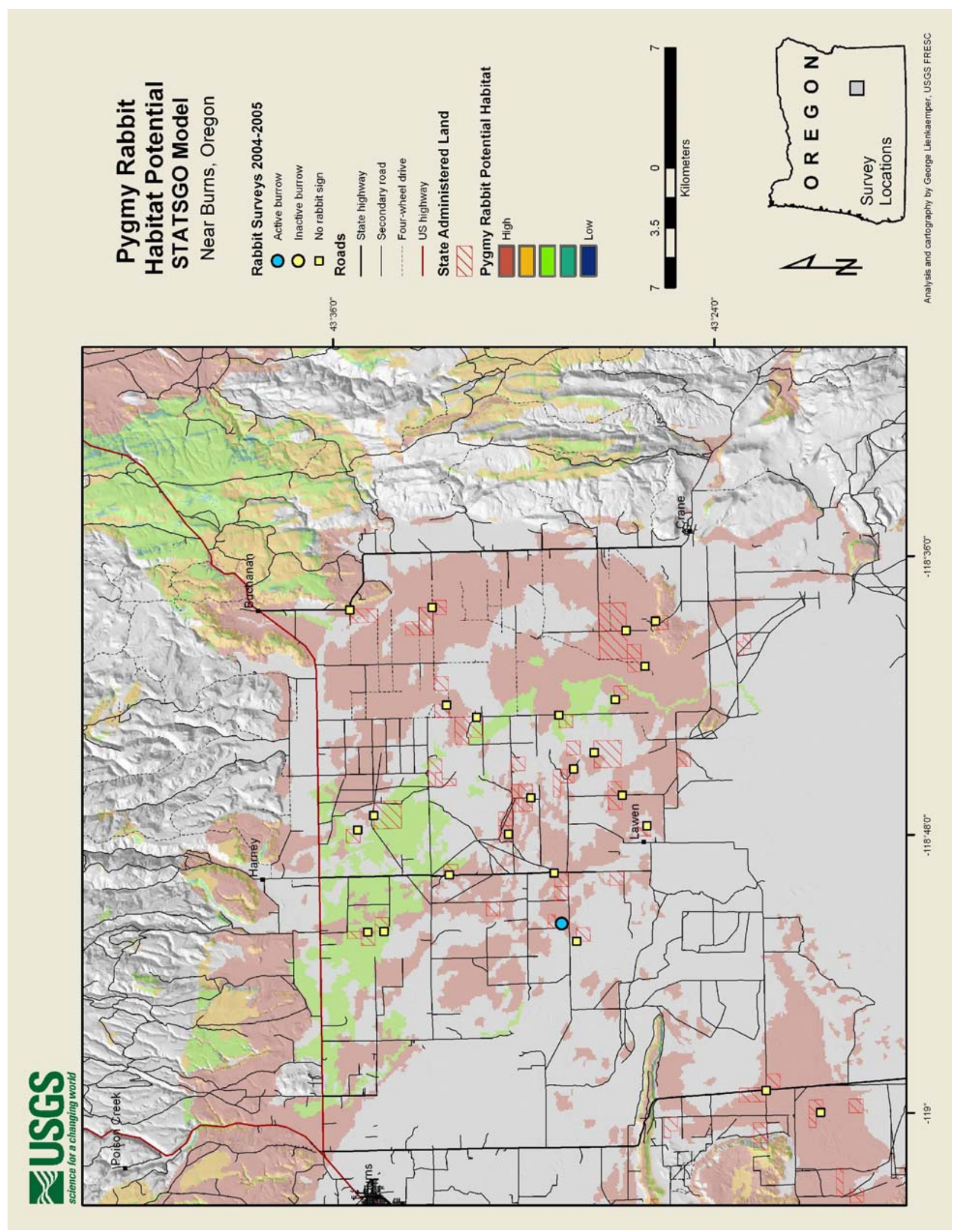




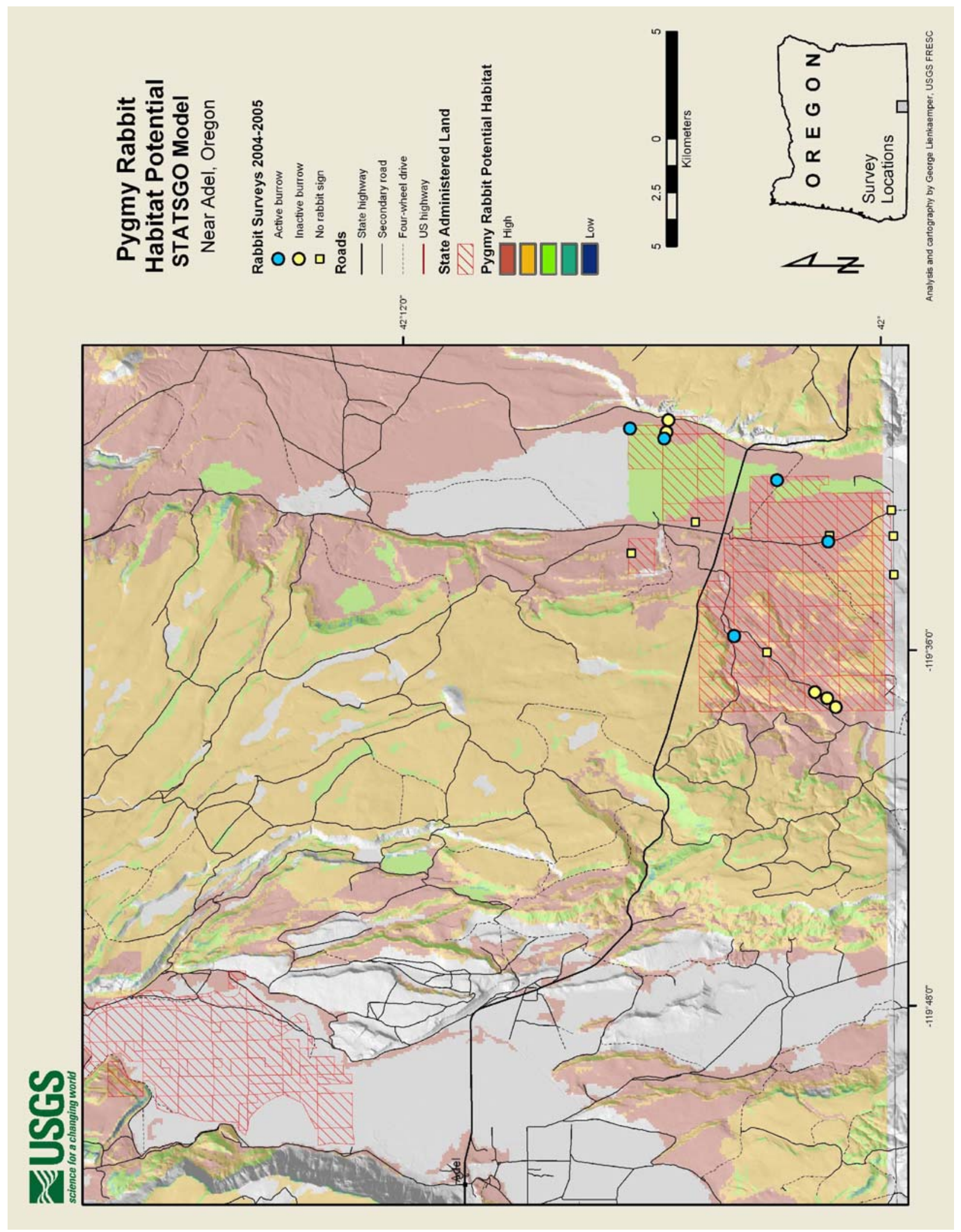




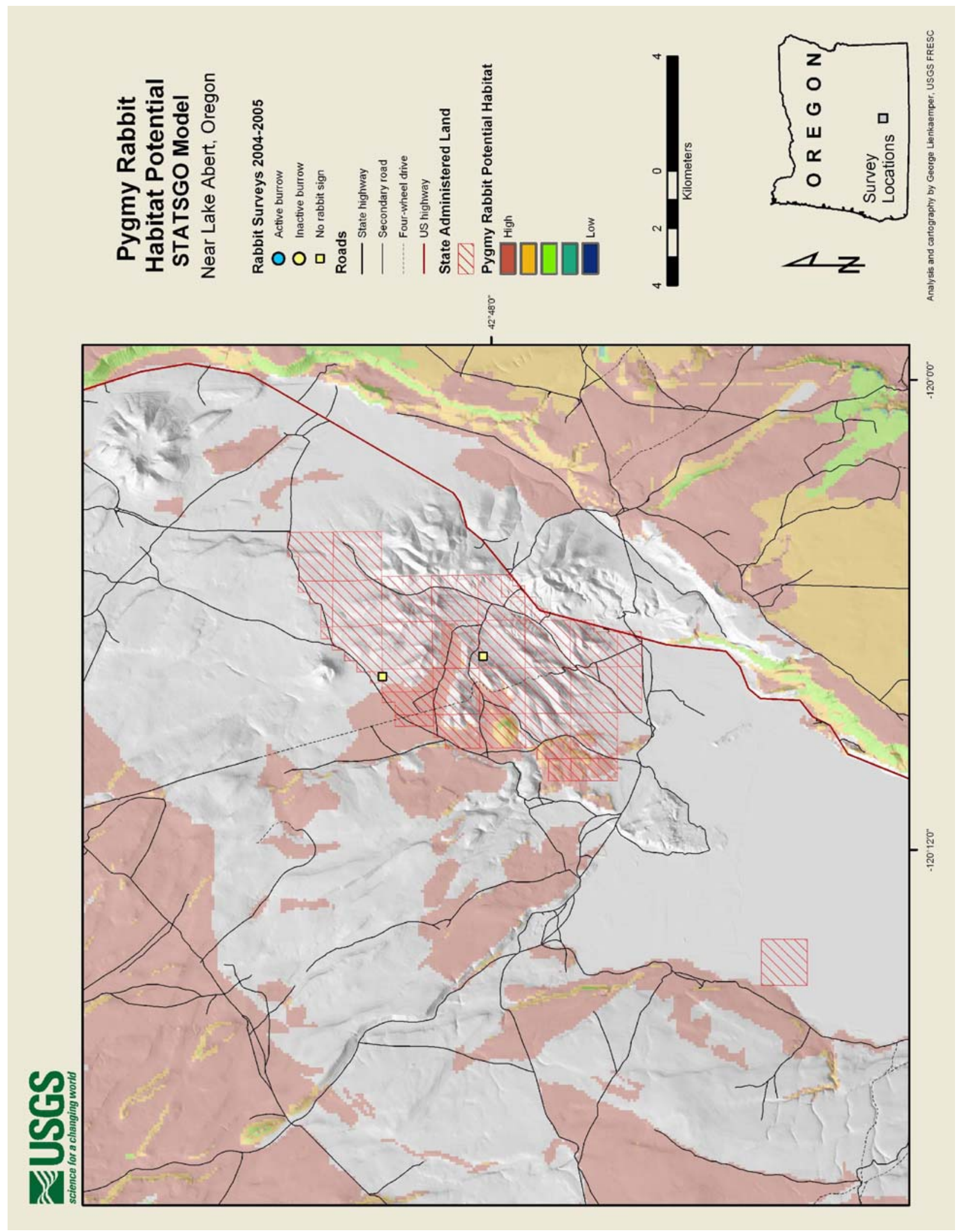




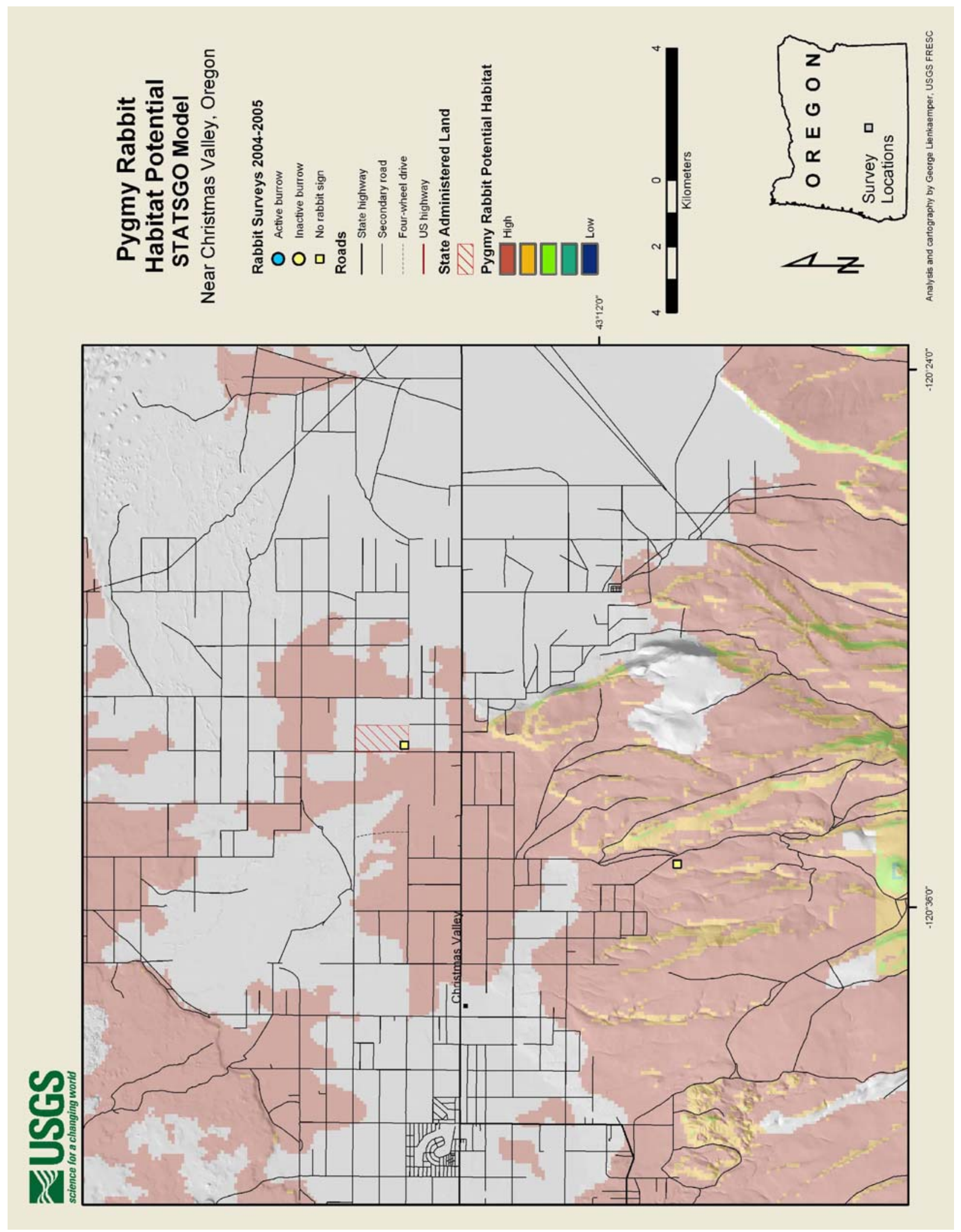




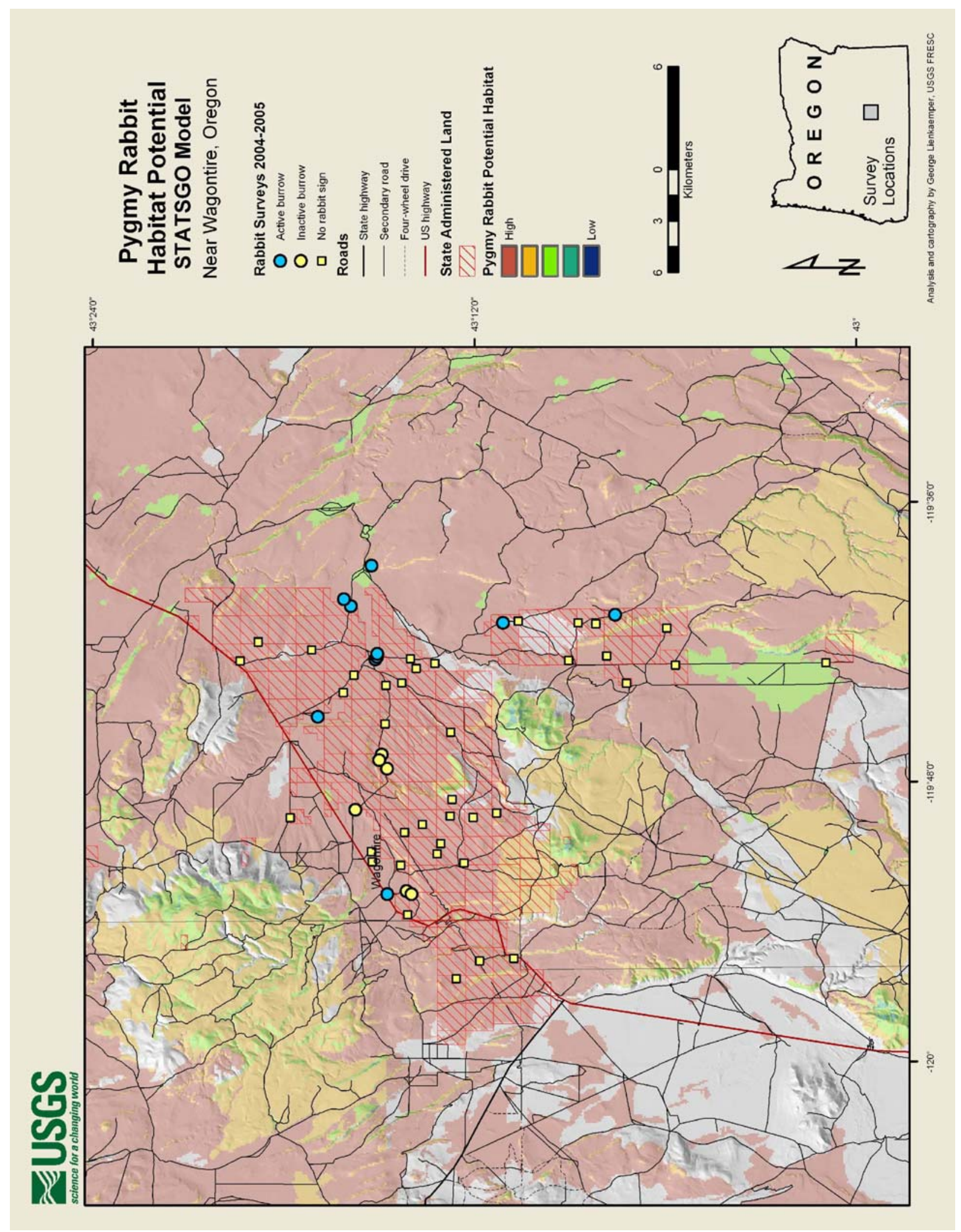




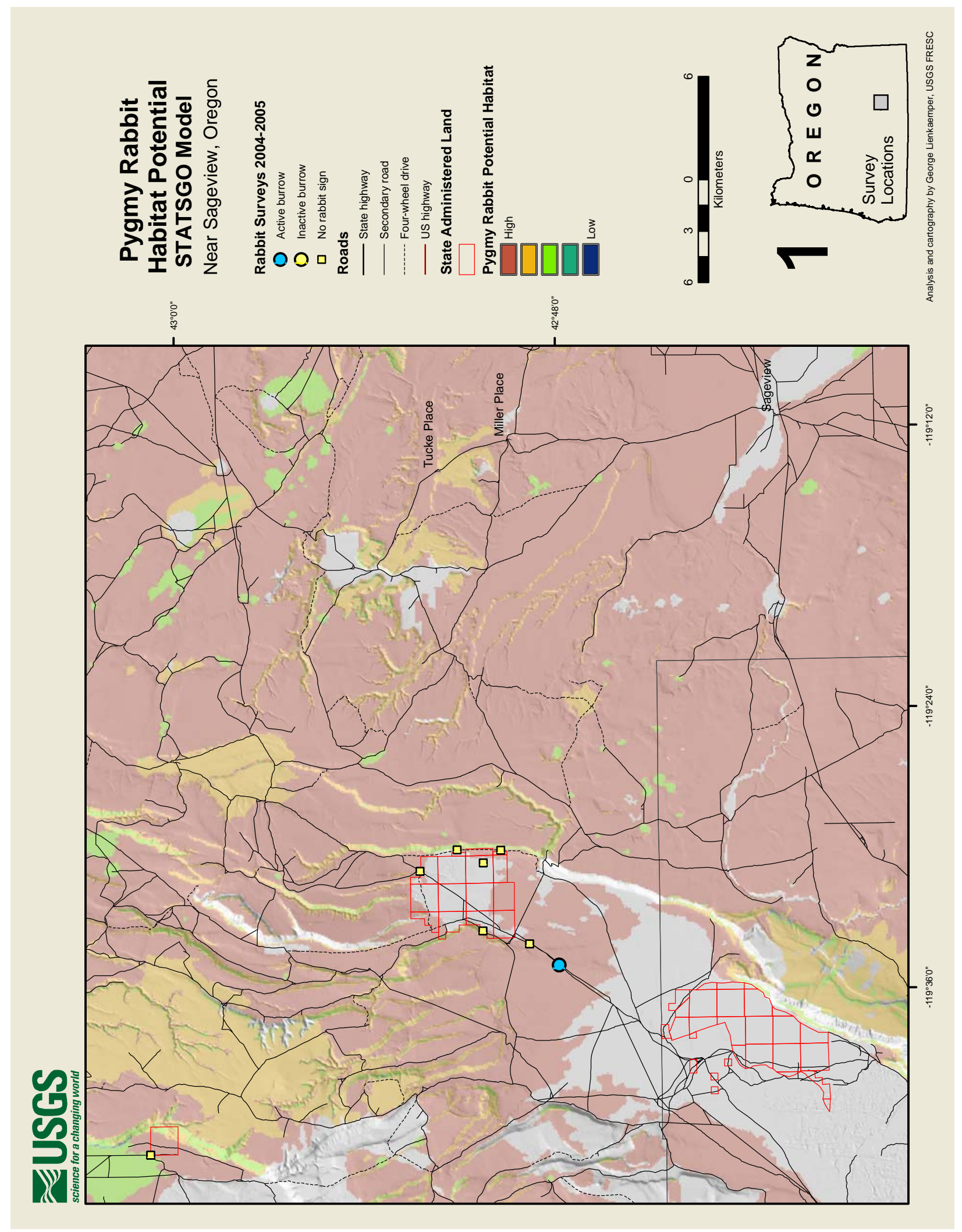




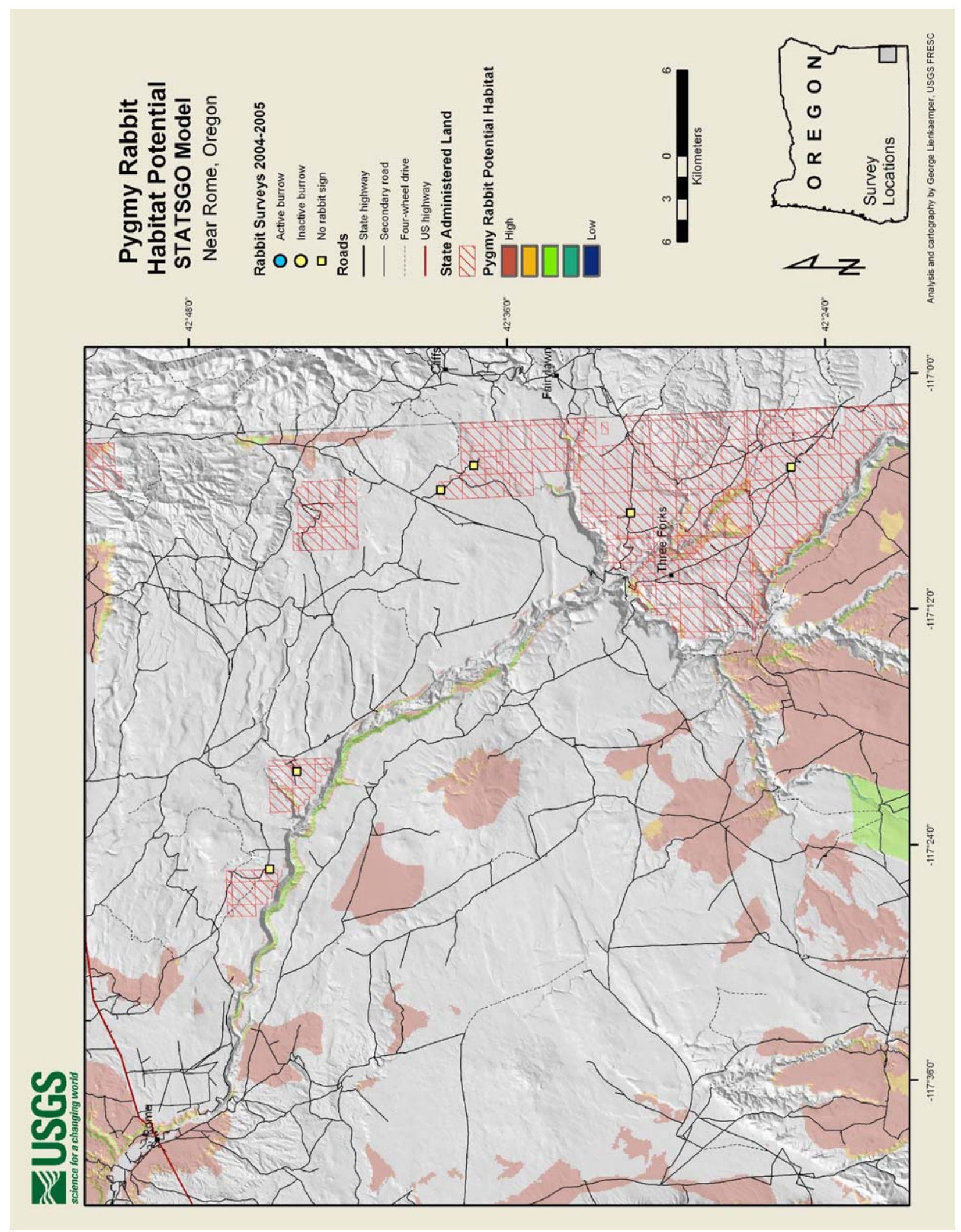




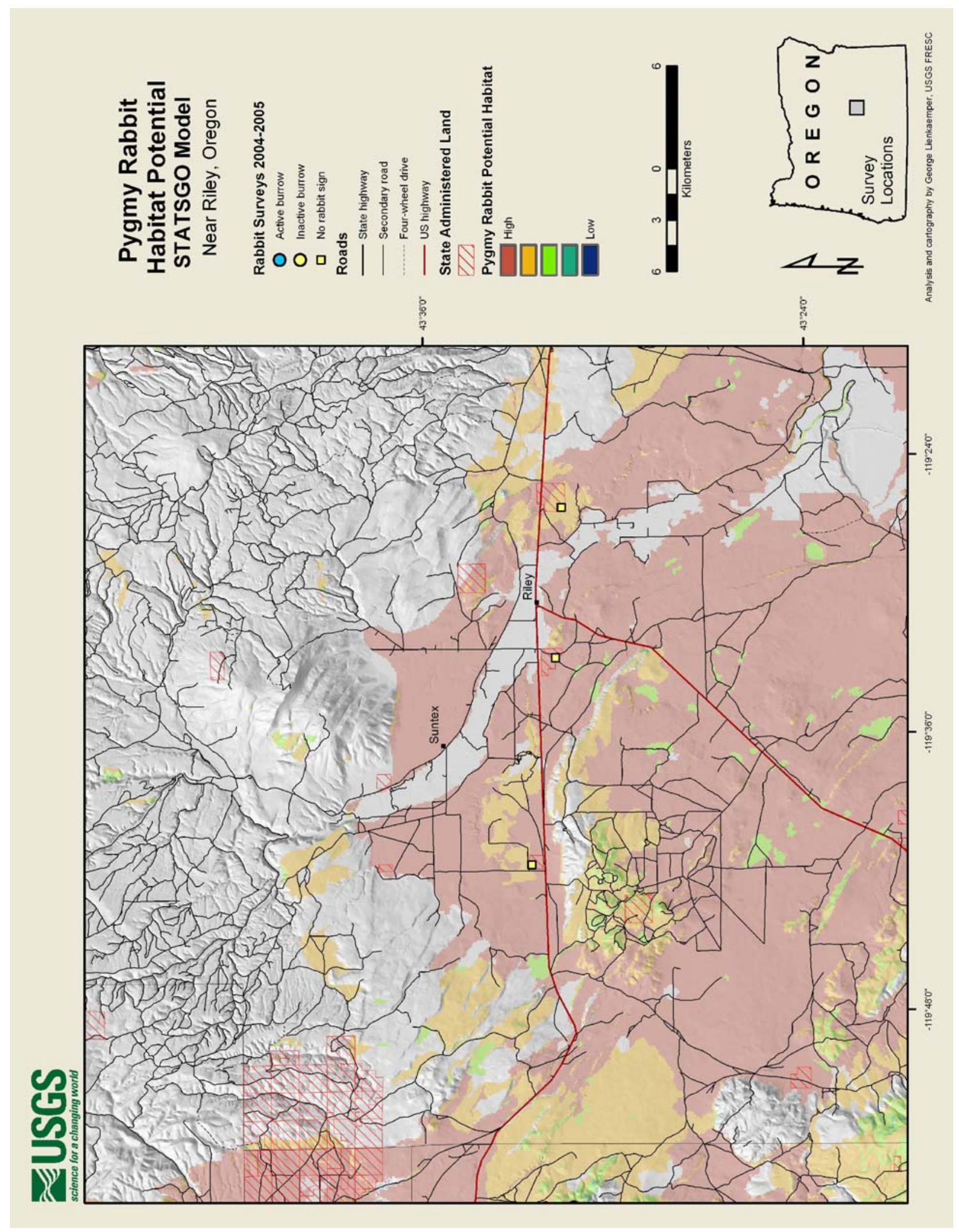




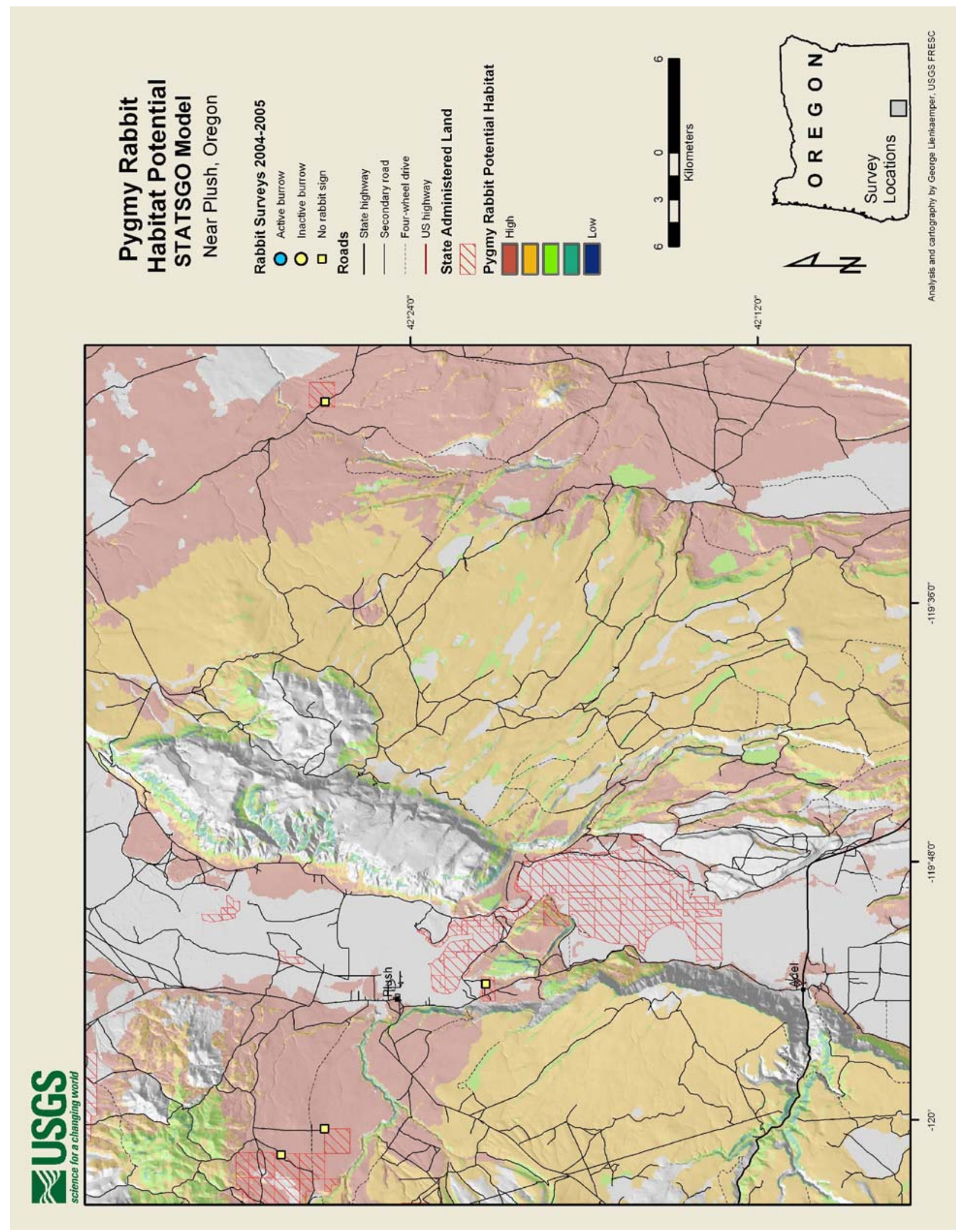




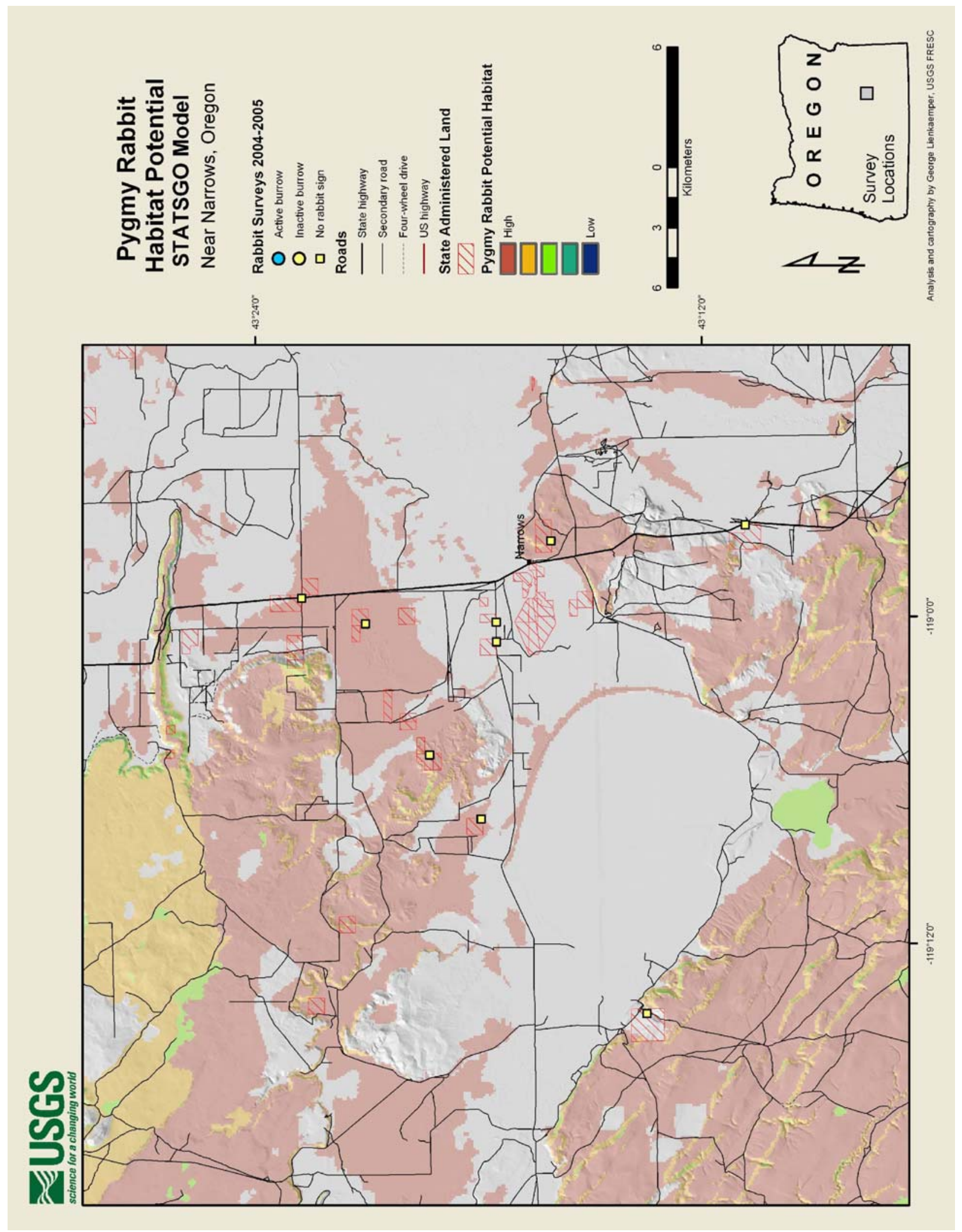




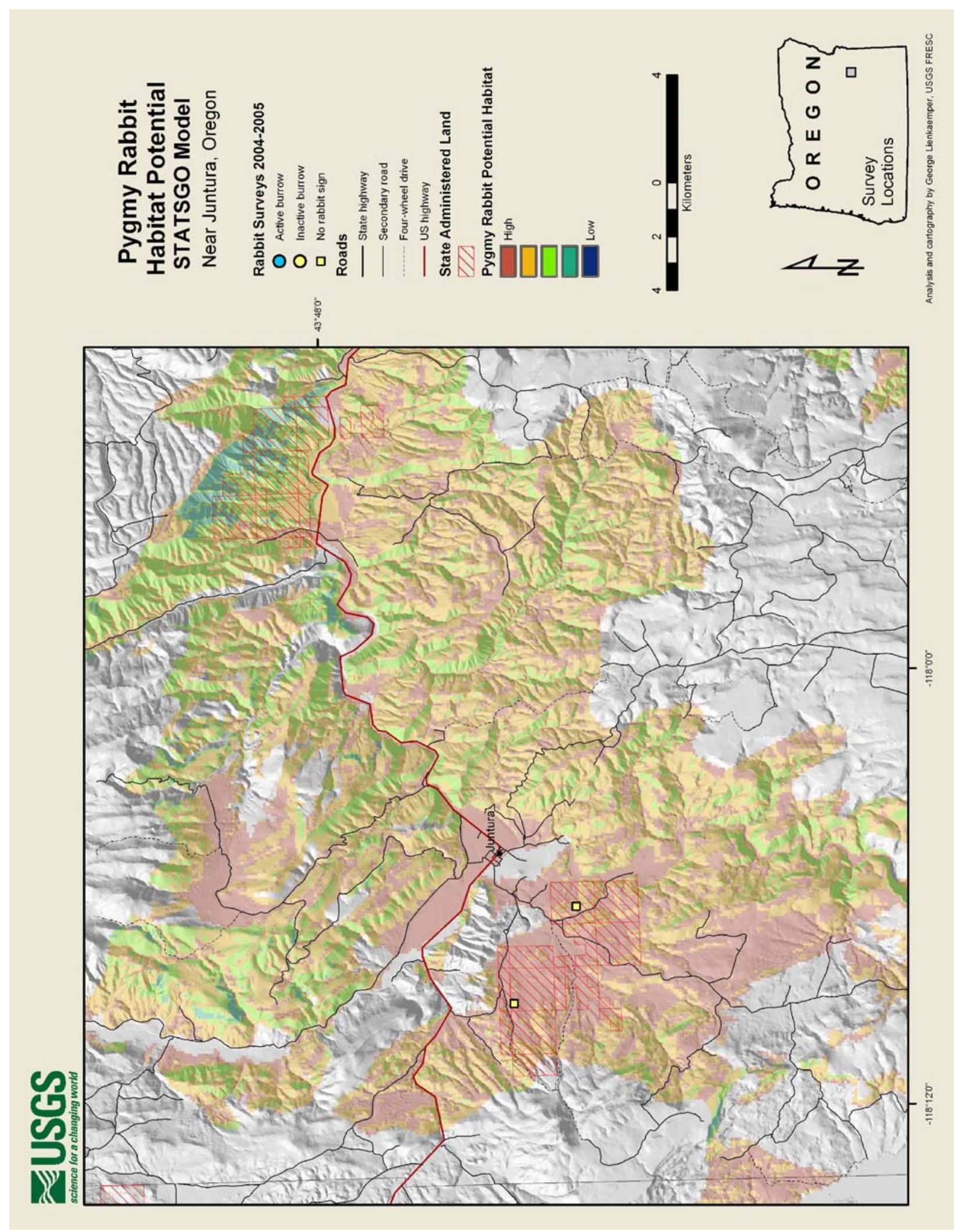

